\title{
NASA looks to overhaul grants process
}

[WASHINGTON] NASA, the US National Aeronautics and Space Administration, has embarked on a sweeping review of its research grants programme, aiming to make it more efficient and responsive to its own needs, and to allay the academic concern about prompt grant payments.

The review, which began last month and will run through the winter, will look at the space agency's entire grants process, from the inception of an idea for a research solicitation to peer review, grant awards, and final work performance and payment. It is being led by Mary Kicza, associate director for space science programmes at the Goddard Space Flight Center in Maryland.

Kicza, who formerly ran the agency's Discovery programme for low-cost planetary missions, says NASA knew it had bottlenecks and other problems in its grants administration. But recent changes have not helped. At the same time as NASA headquarters has been cutting staff, responsibility for administering research grants shifted from there to Goddard, which has had to hire contract officers and learn new procedures.

Meanwhile, pressure to reform is coming from inside and outside the agency. NASA's administrator, Daniel Goldin, for example, has spoken of changing the peer review system to encourage young scientists and unconventional ideas. The White House Office of Science and Technology Policy is eager to improve relations between the government and the universities, and is paying close attention, as is Congress, to complaints from the academic community about NASA's grants process.
One frequent complaint involves delays in payment. Kenneth Baldwin, professor of physiology and biophysics at the University of California at Irvine, and a member of NASA's advisory committee for life and microgravity sciences, said last week that whereas the National Institutes of Health (NIH) generally take three weeks or so to give an initial report on a grant application's scientific merit, NASA can take as long as three months. Other NASA-sponsored scientists report that cheques arrive late, sometimes well after the funding year has begun.

NASA's recent efforts to cut its 'uncosted carryover' budget - approved funds left unspent before the end of a fiscal year, which roll over into the next year - have also imposed hardships on universities, say Kicza and others. In effect, if NASA chooses not to bridge the gap from one funding cycle to the next, universities have to do so.

Life and microgravity scientists, on whom NASA spends about \$114 million a year for 740 grants, have been hit particularly hard by this problem. Because agency programme managers face a funding shortfall in these areas next year, they have been particularly aggressive about reducing their uncosted carryover.

Kicza says her team is eager to hear complaints from the scientific community, and has sent out thousands of letters to individuals and academic institutions to solicit comments. Her office also has a Web site (http://booster.nasa.gov:443/grant) for researchers to fill out a questionnaire online.

At present, she says, the study team is simply taking stock of how NASA's different offices, which fund research in disciplines ranging from astronomy to biology to fundamental physics, process their grants. By early next year, however, they hope to have solutions.

One obvious area to look at, she says, is automation of grant-processing. The National Science Foundation has developed a system whereby grant applicants can send proposals electronically, and the NIH should have a system in place by 1999 . An Interagency Electronic Grants Committee of the Government Services Agency is looking at standardizing techniques for all government granting agencies.

Kicza says her group will consult frequently with other agencies that process grants to see what NASA can learn. Her team's report will be presented to Goldin around March, in time to influence the 1999 budget request.

Tony Reichhardt

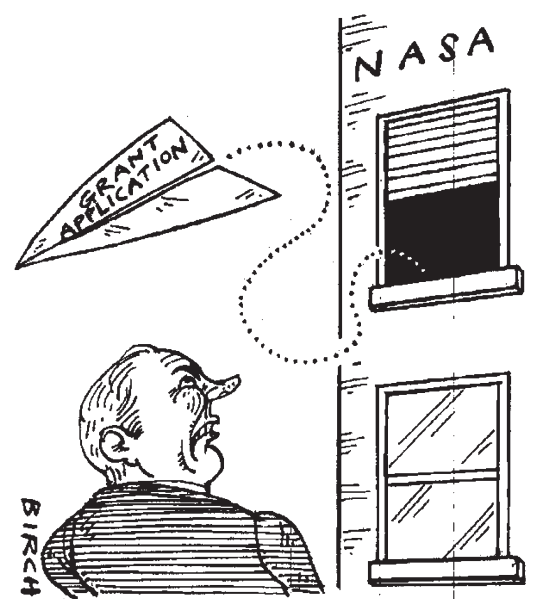

\section{Lack of cash for instruments 'threatens ESA science missions'}

[MUNICH] Future scientific missions of the European Space Agency (ESA) are under threat because member states are not making sufficient money available for the development of scientific instruments.

This was the message from a 'brainstorming' meeting in Oxford, England, last week of ESA's science advisory and science programme committees, and its working groups on astronomy, Solar System science and fundamental physics.

Under ESA rules, the agency pays for satellites and launches but member states must provide instruments for missions in which their scientists participate. The meeting was arranged to discuss responses to financial crises faced by both sides.

ESA has reoriented its long-term space science plan, Horizons 2000. The new plan, presented to the meeting by the agency's executive, abandons the concept of ECU300million (US\$332-million) medium-sized missions in favour of smaller and cheaper 'flexible' missions, including technology testing missions, that can be launched more frequently (see Nature 385, 380; 1997).

ESA's executive said it also hopes to make a one-off saving of more than ECU300 million by placing instruments for the next two missions in the planning stage - the cornerstone FIRST (Far-Infrared Telescope) and the Planck surveyor, a medium-sized mission to study the cosmic-microwave background - on the same satellite (see Nature 387, 639; 1997). The merger is strongly opposed by Planck scientists.

Ironically, says Paul Murdin of the UK Particle Physics and Astronomy Research Council, ESA's attempts to make its science budget stretch further will make it even harder for member states to provide instruments. Delegates said it would be difficult to find cash for instruments for early flexible missions such as Mars express, which ESA hopes will be launched in 2003. In addition, the proposed FIRST-Planck merger, with a planned launch in 2005 or 2006, would bring forward FIRST's launch by two years, putting further pressure on budgets. A firm decision on the merger will be made next June. Meanwhile, a call for proposals for FIRST and Planck instruments will go out in the next few weeks.

No definitive solution to the cash problems was proposed, but "many options for alleviating costs to member states were discussed", says Roger Bonnet, ESA's science director. These included simplifying instruments, and standardizing interfaces between instruments and satellites so costs could be transferred to ESA.

There was some lightening of the gloom with the announcement that NASA would provide a 3.5-metre carbon-fibre telescope for FIRST as a demonstrator in return for 10 per cent of viewing time. 